\title{
The Bulk Carrier Maximum Optimal Ship Size
}

\author{
Eliamin Kassembe ${ }^{1} \&$ Zhao Gang ${ }^{2}$ \\ ${ }^{1}$ Department of Science and Management, Dar es Salaam Maritime Institute, Dar es Salaam, Tanzania \\ ${ }^{2}$ Institute of Transport, SMU, Shanghai, China \\ Correspondence: Eliamin Kassembe, Department of Science and Management, Dar es Salaam Maritime Institute, \\ Sokoine drive, P.O. Box 6727, Dar es Salaam, Tanzania. Tel: 255-786-177-011. E-mail: \\ ekassembe@yahoo.co.uk
}

Received: July 9, 2012 Accepted: December 7, 2012 Online Published: January 20, 2013

doi:10.5539/ijbm.v8n4p44 URL: http://dx.doi.org/10.5539/ijbm.v8n4p44

\begin{abstract}
The main objective of this paper is to investigate the economical limit for the ships' increase in size. Ship size is one factor out of many that affect the investors in the shipping business. The paper seeks to reassess the validity of well-established theoretical frameworks, which support the concept of depending on the increase in size of ships prompted by economies of scale. The investigation was conducted by use of quantitative methods where mathematical modeling and simulations were used to analyze the relationships of the key variables. Computer software like MS Excel 2010 was used to simulate and generate graphs, values and trends.

The empirical results of this work support the theory of economies of scale that can be enjoyed by operating the optimal ship sizes. Optimality of ships, change linearly with changes in voyage length. The central and novel contribution of this paper is about the existence of a threshold point where optimal ship sizes reflex the economical maxima. For the dry bulk sector the maximum optimal ship size determined as 340,000 dwt.
\end{abstract}

Keywords: optimal ship size, maximum optimal ship size, voyage length, ship unit cost

\section{Introduction}

The available literature (Stopford, 2009; ICS, 2008; Kassembe, 2011) indicate that investment in ships is a capital intensive business, and requires a good know-how on the effective strategies that can help investors to stay put in the business. One of those strategies is by operating bigger ships where investors can benefit from the economic concept known as, 'economies of scale'. For that reason, various reports have been published, updating the status of the newbuilding order book and newbuilding deliveries. A trend of ships getting bigger has become steady for some time now (Pinder and Slack, 2004) and has caused discussions in the industry and within the academic communities.

There have been a number of valuable studies on the problems associated with the increase in ships size (Christiansen, et al, 2007; Drewry, 2009), however, none of these studies provide a clear picture for the maximum economic ship size. Taking into consideration the above deficiency, this paper intends to work out the economical limit of ships' increase in size.

The rest of the paper is organized as follows: Section 2, the mathematical modeling is introduced. Section 3 expounds on the optimal vessel size model. Section 4 presents the models' constant values. Finally, Section 5 provides the concluding remarks.

\section{Mathematical Modeling}

In this stage, we begin with scrutinizing the relationship of two fundamental aspects, namely vessel costs and ship size. The use of mathematical model methods was employed in analysis of the relationship that exists between the above two aspects.

The equation below (Eq.1) is an important expression which involves three central factors that affect the voyage unit cost. These factors include the voyage length, $\lambda$, vessel size $V_{s}$ and a constant $k_{v p}$ emanates from ports' influence. The three factors were closely studied to get some more insights about their relationship, their limitations and how they affect the $U_{c}$ when allowed to vary.

In this paper we consider the ship-unit cost model which was developed by Kassembe and Zhao (2011) by 
modifying it to make it more general as,

$$
U_{c}=\frac{k_{n b}}{V_{s}^{\alpha}}+\frac{k_{o p c}}{V_{s}^{\beta}}+\frac{k_{v s} \lambda}{V_{s}^{\frac{1}{2} \gamma}}+k_{v p} V_{s}^{\gamma}+k_{v p}
$$

Where the first term on (1) is taken as the capital cost in the form of new building unit cost, followed by OPEX unit cost, voyage unit cost at sea, voyage unit cost in port, and the $k_{v p}$. Eq. 1 is the overall shipping unit cost and other shipping sectors may use it to calculate their shipping unit costs. Here it should be noted that containership unit cost is not necessarily equal to the tankership unit cost of the same size, because the constants involved in Eq.1 vary with the shipping sector as well as type of ship.

\section{The Optimal Vessel Size Model}

If investors aim at maximizing their benefit of economies of ship size, it is obligatory to determine the optimal vessel size. The obvious approach to achieve the optimal ship size is by differentiatimg the Eq. 1 and subsequently equates $d U_{0} / d V_{0}$ to zero. The results of this process is rearranged to obtain the following differential equation,

$$
\frac{d \lambda}{d V_{o}}=\frac{\alpha r_{1}}{V_{o}^{\alpha-\frac{1}{2} \gamma+1}}+\frac{\beta r_{2}}{V_{o}^{\beta-\frac{1}{2} \gamma+1}}+\frac{\frac{1}{2} \gamma \lambda}{V_{o}}-\frac{\gamma r_{3}}{V_{o}^{1-\frac{3}{2} \gamma}}
$$

Where, $r_{1}=\frac{k_{n b}}{k_{v s}}, r_{2}=\frac{k_{o p c}}{k_{v s}}$, and $r_{3}=\frac{k_{v p}}{k_{v s}}$. Equation (2) redirects the vessel's size to the optimized outlook and the following essential information is encrypted within the equation.

(1) The optimal vessel depends on the interactions between the voyage distance and vessel size. The ratio $d \lambda / d V_{o}$ carries vital information for the interactions.

(2) The optimal vessel size depends on some constants emanating from costs of voyage in sea and in port, capital cost, and operating cost.

(3) The constants $\alpha, \beta, k_{n b}, k_{o p c}, k_{v s}$ and $k_{v p}$, vary with ship type, age of ship and time.

(4) Optimal vessel size varies with ship type and/or the shipping sector in general.

The four bits of information given above were verified through the use of simulation. The use of simulation method is indispensable for data analysis and for debunking of some hiden but useful information.

\section{Models' Constant Values}

The most challenging part in the model implementation was the choice of correct constant values. It could not have been possible to run the simulation without the knowledge of key values of some constants and coefficients given in model 2. Table 1 provides the values of the constants used in simulation:

Table 1. Simulation model constant values for the bulk carrier new building

\begin{tabular}{lccccccc}
\hline & & & & New building & OPEX & Voyage at port & Voyage at sea \\
\hline Constants & $\alpha$ & $\beta$ & $\gamma$ & $\mathrm{k}_{\mathrm{nb}}$ & $\mathrm{k}_{\mathrm{opc}}$ & $\mathrm{k}_{\mathrm{vp}}$ & $\mathrm{k}_{\mathrm{vs}}$ \\
Values & $\mathbf{0 . 4 7 3}$ & $\mathbf{0 . 7 1 9}$ & $2 / 3$ & $\mathbf{1 2 6 , 2 5 8}$ & $\mathbf{2 6 0 . 1 1}$ & $\mathbf{0 . 9}$ & $\mathbf{3 . 6}$ \\
\hline
\end{tabular}

The values for the constants in Table 1 were established by the use of mainly three different methods as follows:

(1) Empirical methods

This method was used to determine the values of the constants $\alpha, \beta, \mathrm{k}_{\mathrm{nb}}$ and $\mathrm{k}_{\mathrm{opc}}$.

(2) Mathematical deduction

Mathematical deduction was used to determine the value of the constant $\gamma$

(3) Estimation

Through close observations it was possible to follow the responses of the model on different values.The MS 
Excel 2010 was used to determine the values of $\mathrm{k}_{\mathrm{vp}}$ and $\mathrm{k}_{\mathrm{vs}}$.

However, it should be born in mind that, the values in Table 4.1 can slightly vary with data alterations. Changes in capital cost and the OPEX costs, can contribute significantly to changes in the constants. As well, they can change with different type of vessels, age of vessels and the state of the world economy at a particular time.

\subsection{Ship Unit Cost $\left(U_{c}\right)$ and Ship Size $\left(V_{s}\right)$}

Through graphical illustration of the relationship between ship unit cost with ship size, some remarkable patterns were revealed as shown in Fig. 1. These patterns were noted for further analysis and interpretations.

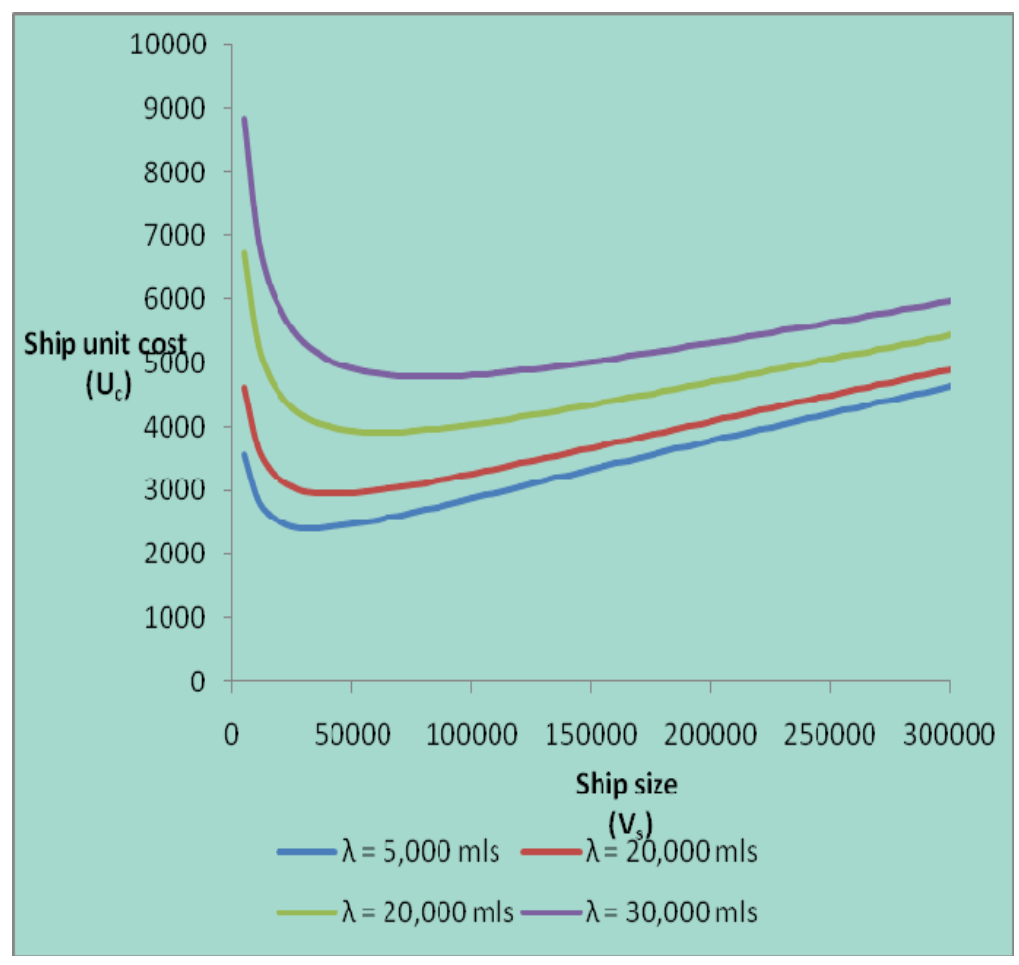

Figure 1. The relationship between dry bulk carrier ship unit cost and ship size for different voyage lengths

The observable patterns in Fig. 1 include;

1) The graph of relationship between unit cost and vessel size demonstrates a roughly U-shaped curve when a voyage length is assumed to be constant.

2) The minimum point in the curve suggests the minimum ship unit cost

3) The minimum point in the curve infers to a certain ship size

4) The minimum point changes with variations of the proposed voyage length

5) Every change in the voyage length triggers two concurrent changes which are associated with the minimum point. These include: (1) the vertical changes and (2) horizontal changes. The above changes can be well represented by the following expression,

$$
d \lambda=\omega d U_{c}+\varphi d V_{s}
$$

Where, $\boldsymbol{\omega}$ represents the number of vertical movements while $\varphi$ represents the number of movements in the horizontal direction. If we divide Eq. 3 by $V_{s}$ throughout, we obtainthe expression 4 as,

$$
\frac{d \lambda}{d V_{s}}=\omega \frac{d U_{c}}{d V_{s}}+\varphi
$$

Eq. 4 suggests that, the changes in the minimum point are caused by interactions between voyage length and 
vessel size. The component $d \lambda / d V_{s}$ depends on the effects which are caused by the ratio $d U_{c} d d V_{s}$ and the vertical interception point given by $\varphi$.

Now, it is imperative to note that, from the above facts, the minimum point relates to the optimal vessel size. Hence, it can now be asserted that the optimal ship size is strictly a function of voyage lengths $V_{0}=f(\lambda)$. However, the challenge here is on how to formulate the function so that one can predict the optimal ship size. The following sections unmask the poser.

\subsection{Voyage Length $(\lambda)$ and Optimal Ship Size $\left(V_{o}\right)$}

Analysis of data pertaining the relationship between $\lambda$ and $V_{o}$ derive a clear picture of relationship between the optimal ship sizes and the voyage lengths. The graph of $\lambda$ against $V_{o}$ generated in Fig. 2 appears to be represented by a straight line embroiled with triangular waves. The triangular wave pattern is due to the fact that the frequency of change of $\lambda$ is higher than that of $V_{o}$. However, by inserting a trend line, it appears that the statistical measure of how well a regression line approximates real data points is $\mathrm{R}^{2}=99.62 \%$. This is implies that there is a high strength of relationship between $\lambda$ and $V_{o}$, and a mathematical model thereof, is reliable and can be used to forecast optimal ships for various voyages (Eq. 5).

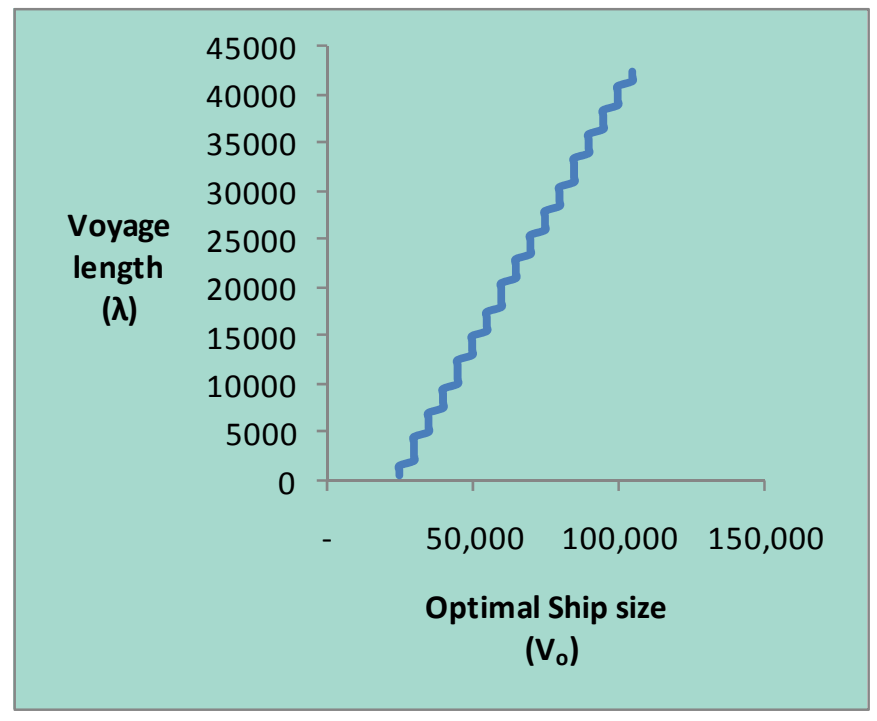

Figure 2. Variation of optimal ship size over voyage length

Despite the presence of wavy appearance in the graph, the overall trend is evidently a linear proportionality with $d \lambda / d V_{o}=m$. The constant $\boldsymbol{m}$ represents slope of the graph. By the aid of computer softwere the linear equation of relationship between the optimal vessel size $\left(V_{o}\right)$ and voyage length $(\lambda)$ was generated as,

$$
\lambda=0.5528 V_{0}-12234
$$

From the equation 5 we obtain $m \approx 0.52$ which implies that the horizontal values change faster than vertical values. However, the line in Fig. 4.2 does not pass through the origin, instead it has the vertical intercept value of $\lambda_{0} \approx-12234$; this is attributable to the fact that the smallest optimal ship cannot be equal to zero. The smallest optimal ship size can be determined by setting $\lambda=0$ and work out for $\mathrm{V}_{\mathrm{o}}$. After working out through this step the value of $V_{0} \approx 23,400 d w t$ was generated.

\subsection{Ship Unit Cost $\left(U_{c}\right)$ and Optimal Ship Size $\left(V_{o}\right)$}

In this step the pairs of data of $\left(U_{c}, V_{o}\right)$ were used and the graph in Fig. 3 was generated to portray the relationship between $U_{c}$ and $V_{o}$. 


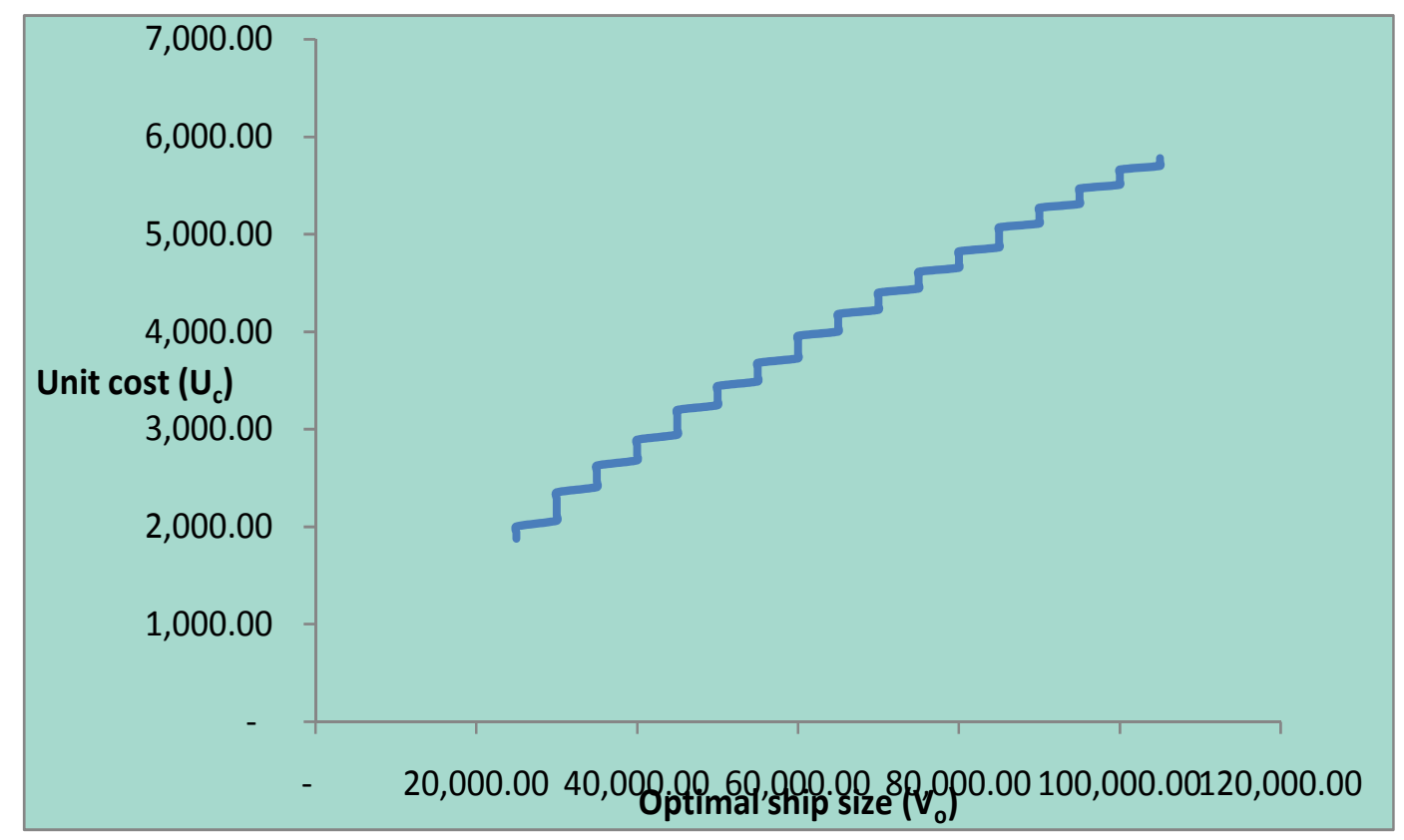

Figure 3. The relationship between ship unit cost $\left(\mathrm{U}_{\mathrm{c}}\right)$ and optimal ship size $\left(\mathrm{V}_{\mathrm{o}}\right)$

Fig. 3 displays a concave function with triangular waved pattern. By use of the MS Excel 2010, a trend line with $\mathrm{R}^{2}=99.61 \%$ and Eq. 6 were added. The Eq. 6 portrays a quadratic polynomial, implying the presence of a maximum point $\left(\mathrm{U}_{\max }\right)$. The maximum point $\left(\mathrm{U}_{\max }\right)$ corresponds to a maximum optimal ship size $\left(\mathrm{V}_{\max }\right)$. The $\mathrm{V}_{\max }$ is calculated from the equation 6 as follows,

$$
U_{c}=-1 \times 10^{-7} V_{o}^{2}+0.0671 V_{o}+347.7
$$

Taking derivatives on both sides we obtain the linear expression, and equate it with zero to evaluate the $V_{\max }$, as shown below

$$
\frac{d U_{c}}{d V_{o}}=-2 \times 10^{-7} V_{o}+0.0671=0
$$

\section{$V \max =340,000 d w t$}

When $V_{\max }=340,000 \mathrm{dwt}$ is substituted into Eq. 6 the value of a ship unit cost equal to US\$11,602 is achieved. Thus the concept of maximum optimal ship exists and serves as a caution for investors intending to operate bigger ships.

\section{Conclusion}

This work confirms that the ship unit cost decrease with the increase of ship size for some time, and that the changes in unit cost drive the growth of ship sizes. The decrease in unit costs continues until when the minimum value is reached. The vessel size related with the minimum unit cost is regarded as the optimal ship size from which the owner enjoys the minimum shipping unit costs. In economics perspective, this is considered as making business from the optimal ship size.

Further analysis shows that the changes in the optimal ship size are strongly influenced by the voyage length where a change in voyage distance triggers the concurrent vertical and horizontal changes. These changes are well modeled by the equation $d \lambda=\omega d U c+\varphi d V s$. However, Eq. 6 can be used to predict the $\mathrm{V}_{\mathrm{o}}<\mathrm{V}_{\max }$ for every $\lambda$ with a strength of relationship of $99.62 \%$. Eq. 5 suggests that the changes in the optimal ship size are direct proportion to the changes in the voyage length.

Finally, it has been proven that, the cost advantage that exists in operating big ships is available in the range $V_{o}<V_{\max }$. In this context the owners that operate the optimal ships with size above the maximum size $\left(V_{\max }\right)$ cannot spawn a positive cashflow in their business. Thus, the $V_{\max }$ for a particular shipping sector is the threshold of benefits that can be offered by economies of scale. The $V_{\max }$ is the point where voyage costs begin to outweigh 
the benefits of change in ship unit cost. It is similar to the Hooke's law which is only valid for the elastic range before the elastic limit at the yielding point.

However, the $\mathrm{V}_{\mathrm{o}}<\mathrm{V}_{\max }$ range can considerably vary when we change shipping sectors or simply the constant values given in Table 4.1, otherwise $V_{\max }=340,000 \mathrm{dwt}$.

\section{References}

Christiansen, M., Fagerholt, K., Nygreen, B., \& Ronen, D. (2007). Maritime transportation. Handbooks in

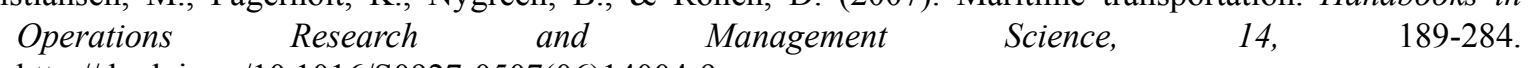
http://dx.doi.org/10.1016/S0927-0507(06)14004-9

Drewry. (2009). Shipping Insight: monthly analysis of the shipping market.

ICS. (2008). Economics of sea Transport and International Trade. Witherby Seamanship International Ltd., UK.

Kassembe, E., \& Gang, Z. (2011). The impact of ship size on its unit cost. 2011 International Conference on Transportation and Mechanical \& Electrical Engineering (TMEE 2011), Chang chun, China.

Pinder, D., \& Slack, B. (2004). Shipping and Ports in the Twenty-first Century: Globalization, technological change and the environment. Routledge Taylor \& Francis Group, London and NY. http://dx.doi.org/10.4324/9780203496411

Stopford, M. (2009). Maritime Economics. Routledge Taylor \& Francis Group, London and NY. http://dx.doi.org/10.4324/9780203891742 